\title{
Combined prednisolone and intravenous immunoglobulin treatment for acquired factor VIII inhibitors: a 2-year review
}

\author{
A. C. DYKeS, I. D. WALKER, G. D. O. LOWE and R. C. TAIT \\ Haemophilia Centre, Glasgow Royal Infirmary, Glasgow, UK
}

Summary. Acquired inhibitors to factor VIII (FVIII) are rare, but life-threatening in up to $22 \%$ of cases. The optimal therapy for suppression of these inhibitors remains unclear. Prednisolone is the mainstay of therapy, producing responses in approximately $30 \%$ of cases. Intravenous immunoglobulin (IVIg) has a similar response rate, but a more rapid effect. We report the results of prednisolone $1 \mathrm{mg} \mathrm{kg}^{-1}$ combined with IVIg $2 \mathrm{~g} \mathrm{~kg}^{-1}$ in divided doses as first-line therapy in seven consecutive patients with acquired FVIII inhibitors. All patients were bleeding at the time of diagnosis with prolonged activated partial thromboplastin time.
There were four complete responses, one partial response, one nonresponse and one with an inadequate follow-up for assessment of response, giving an overall response rate of $71 \%$. In all complete responders the inhibitor declined rapidly and was undetectable by day 21 from start of treatment. Therapy was well tolerated and responses have been maintained off treatment for 2-8 months. This is a safe, well-tolerated rapidly acting regimen with good response rates.

Keywords: acquired haemophilia, factor VIII inhibitor, factor VIII, immunosuppressive therapy.

\section{Introduction}

Acquired inhibitors to Factor VIII in nonhaemophiliac patients are rare, but serious, having an incidence of $1-4$ million $^{-1}$ year $^{-1}[1,2]$. These inhibitors are autoantibodies, usually IgG and polyclonal in nature. The majority occur in older people, with a median age at presentation of 60-67 $[1,3,4]$, although they may also occur during pregnancy and in the postpartum period. Fifty percent of cases have identifiable associated conditions, including pregnancy, malignancy and autoimmune disease. Serious bleeding occurs in up to $87 \%$ of cases and between 13 and $22 \%$ die due to uncontrolled haemorrhage, usually within a few weeks of presentation $[4,5]$.

Treatment consists of immunosuppression, most commonly using steroid to suppress the inhibitor, and factor replacement to control haemorrhage if appropriate. Prednisolone $1 \mathrm{mg} \mathrm{kg}^{-1} \mathrm{day}^{-1}$ suppresses around $30 \%$ of acquired inhibitors, and a response

Correspondence: R.C. Tait, Haemophilia Centre, Glasgow Royal Infirmary, 86 Castle St, Glasgow G4 OSF, UK.

Tel.: + 44141211 5168; fax: + 44141211 4931;

e-mail: campbell.tait@northglasgow.scot.nhs.uk

Accepted 18 October 2000 will usually be seen within 3-6 weeks $[4,6,7]$. A response rate of $30 \%$ has also been reported for intravenous immunoglobulin (IVIg) alone. This is thought to be an anti-idiotypic effect with responses seen within 5 days [8]. Combination therapy with prednisolone and cyclophosphamide produces responses in $60-70 \%$ [7,9]. Other immunosuppressive regimens have varying success [10-12]. Likelihood of response to treatment cannot be predicted from clinical parameters, although in pregnancy-related inhibitors, spontaneous remission is likely.

The use of prednisolone and IVIg together is appealing, as the combination may produce a more rapid response than either agent alone, without the toxicity seen in more immunosuppressive regimens. There are few published reports of this combination but it is recommended as first-line therapy in some countries [13]. We report here on 2 years' experience of initial treatment of acquired FVIII inhibitors using a standard regimen of prednisolone $1 \mathrm{mg} \mathrm{kg}^{-1} \mathrm{day}^{-1}$ and IVIg $2 \mathrm{~g} \mathrm{~kg}^{-1}$ in divided doses.

\section{Patient details \& laboratory evaluation}

Between June 1998 and June 2000 seven patients with newly diagnosed acquired inhibitors of FVIII 
were treated. There were four males and three females, with a median age of 77 years $(65$ years 83 years). Four of the patients gave a history of minor bleeding over the preceding weeks to months. All patients had active bleeding and a prolonged activated partial thromboplastin time (APTT) at the time of presentation.

FVIII activity was measured with a one-stage APTT based system using FVIII-deficient plasma (Diagen, Oxon, UK). Where results were nonlinear, the FVIII level was taken from the 1:5 dilution. The FVIII inhibitor assay was carried out according to the Bethesda method [14] without the Nijmegen modification. IgG and IgM anticardiolipin antibodies (ACA) were measured by ELISA (Cambridge Life Sciences, Cambridge, UK) and functional lupus inhibitor studies were performed (dilute Russell Viper Venom Test (dRVVT); Diagen), with confirmatory testing by platelet neutralization.

\section{Therapy}

All patients received standardized treatment with The IVIg was initially divided into two daily doses (patients 2 and 5) but later given over 5 days to reduce the risk of developing acute renal impairment [15]. Prednisolone was given at $1 \mathrm{mg} \mathrm{kg}^{-1}$ for 2 weeks then tapered. Blood products were administered based on clinical judgement of severity of bleeding.

Criteria for assessing response to therapy were those defined by Spero et al. A complete response (CR) was defined as disappearance of the inhibitor, improvement of the FVIII activity to greater than $50 \mathrm{IU} \mathrm{dL} \mathrm{d}^{-1}$ and cessation of bleeding. A partial response (PR) involved a decrease of inhibitor titre of greater than $75 \%$, improvement in the FVIII activity to less than $50 \mathrm{IU} \mathrm{dL}$ and/or improvement in haemorrhagic signs. No response (NR) was a failure to improve or worsening of laboratory and/or clinical findings after at least 14 days of treatment [6].

\section{Results}

Table 1 summarizes the main clinical and laboratory details and outcomes of the seven patients. One patient with recurrent squamous cell carcinoma died within 3 months of diagnosis of the inhibitor. Response to treatment in this patient could not be assessed as he was discharged to terminal care after 12 days, at which time there was no improvement in FVIII activity. All other patients are surviving with prednisolone $1 \mathrm{mg} \mathrm{kg}^{-1} \mathrm{day}^{-1}$ and IVIg $2 \mathrm{~g} \mathrm{~kg}^{-1}$.

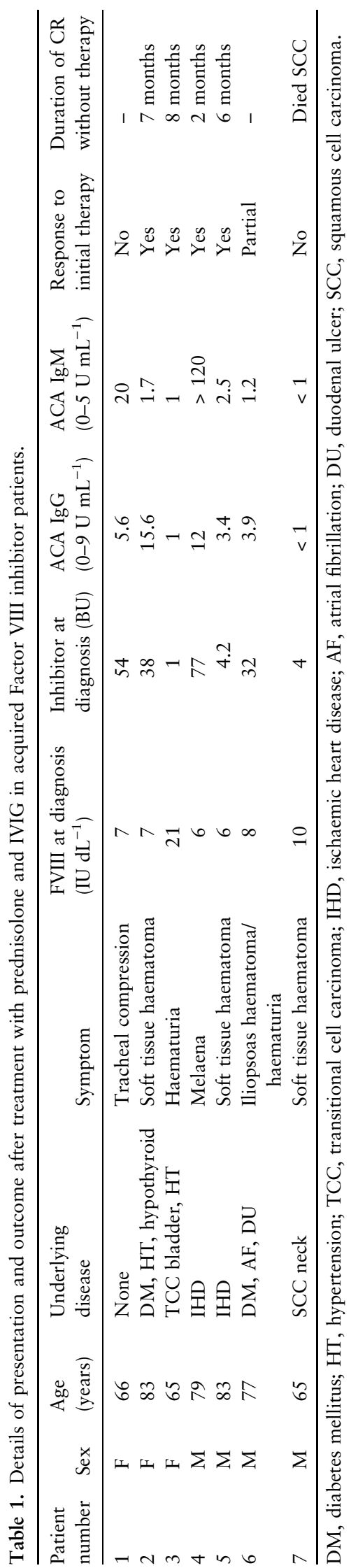

(C) 2001 Blackwell Science Ltd 
no evidence of bleeding, with a median follow-up time of 10.5 months (3-24 months).

FVIII activity at diagnosis was $<10 \mathrm{IU} \mathrm{dL}^{-1}$ in all but one case (patient 3, $21 \mathrm{IU} \mathrm{dL}^{-1}$ ). Inhibitor levels at diagnosis ranged from 1 to 77 Bethesda units (BU), with four being above $10 \mathrm{BU}$. Three patients (patients 1, $2 \& 4$ ) had raised anticardiolipin antibodies (ACA) at diagnosis, two had raised IgM levels $\left(20\right.$ and $>120 \mathrm{U} \mathrm{mL}^{-1}$; normal 0-5 $\mathrm{U} \mathrm{mL}^{-1}$ ) and two had raised IgG (12 and $15.6 \mathrm{U} \mathrm{mL}^{-1}$; normal $\left.0-9 \mathrm{U} \mathrm{mL}^{-1}\right)$. Patient 7 was positive for lupus anticoagulant. In all other patients this test was normal.

\section{Response to IVIg and prednisolone}

Serial FVIII activities and inhibitor levels for all patients are shown in Fig. 1. Four patients attained $\mathrm{CR}$, with a rapid reduction of inhibitor titres, all being undetectable by day 21 (median 5.5 days). Transfusion-independent FVIII activity of $>20$ IU $\mathrm{dL}^{-1}$ was reached at a median of 14 days (range 5-35 days), and $>50 \mathrm{IU} \mathrm{dL}^{-1}$ at a median of 31 days (8-150 days). One patient (patient 6)
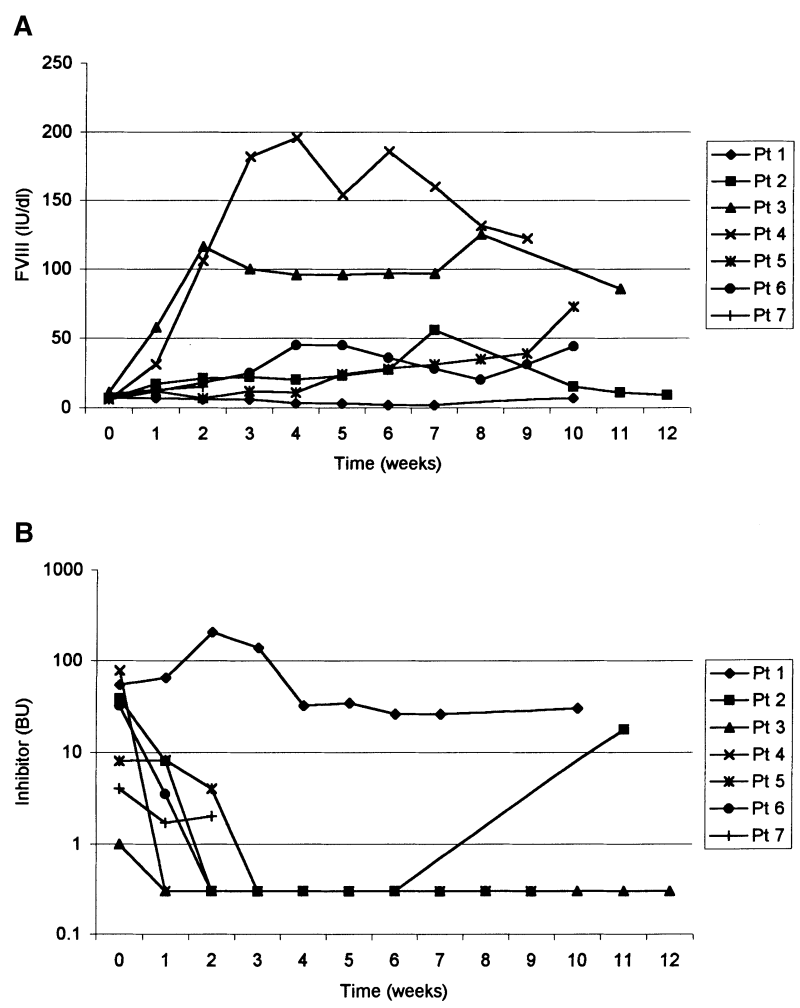

Fig. 1. (A,B). FVIII activity and inhibitor levels for all patients over the first 12 weeks from diagnosis. Inhibitor levels are shown on a logarithmic scale. Inhibitor levels below the level of detection are arbitrarily shown as $0.3 \mathrm{BU}$. attained a PR; the inhibitor level became undetectable and the FVIII activity rose to $>20 \mathrm{IU} \mathrm{dL}^{-1}$ by day 28 , but the FVIII failed to normalize despite the subsequent addition of cyclophosphamide. There was one nonresponder (patient 1) who presented with life-threatening tracheal compression requiring tracheostomy because of a spontaneous haematoma and an inhibitor level of $54 \mathrm{BU}$, subsequently rising to $205 \mathrm{BU}$. Only after 9 months and additional cyclophosphamide did the inhibitor titre become undetectable. FVIII activity remained poor, ranging between $8 \mathrm{IU} \mathrm{dL}^{-1}$ and $40 \mathrm{IU} \mathrm{dL}^{-1} 18$ months after diagnosis.

Six of the seven patients were noted to have significant bleeding at the time of diagnosis. Five were treated with FVIII concentrate and four with prothrombin complex concentrate (three were given both).

One patient (patient 2) relapsed 2 months after diagnosis as the prednisolone dose was tapered, but responded to increased prednisolone and the addition of cyclophosphamide. Of the four patients who attained CR (including the second remission in patient 2), normal FVIII activity has been maintained without treatment for 2-8 months.

\section{Discussion}

Over a period of 2 years, our institution has treated seven patients with acquired inhibitors to FVIII. An eighth case was treated locally. Thus, the annual incidence in this area (covering approx 2.5 million) is 1.8 million $^{-1}$, a figure in keeping with other estimates [1]. Although several patients had pre-existing illnesses such as diabetes and ischaemic heart disease, these may simply reflect the age of the population. Two patients had malignancy related to the formation of their inhibitor. Thus underlying pathology was established in only $29 \%$ of cases, which is less than the often quoted $50 \%$, but similar to that found by others [12].

Although there is good evidence that some inhibitors remit spontaneously, this occurs in less than one-third of patients [1], partially treated patients remain at risk of haemorrhage-related death [6]. Therefore, effective suppression of inhibitor with normalization of FVIII levels is the goal of treatment. Treatment regimens must be suitable for the patients, who are typically elderly, often with multiple coexisting diseases. Prednisolone is well tolerated and IVIg-related renal impairment can be avoided by dividing the dose over 5 days.

The overall response rate for IVIg and prednisolone as primary therapy in this series is $5 / 7(71 \%)$. 
This is better than for prednisolone or IVIg alone (each around $30 \%$ ) [6,8], but is similar to that reported for cyclophosphamide plus prednisolone $[4,7]$. Lian et al. used combination chemotherapy (cyclophosphamide, vincristine, prednisolone) with FVIII concentrate infusion successfully in 11/12 patients, who required between one and three courses to achieve prolonged remissions [11]. However, this impressive result was at the cost of significant neutropenic side-effects, and we feel this regimen is too toxic as a first-line therapy.

There was a rapid drop in inhibitor level in the responding patients, becoming undetectable by day 21 in all CRs, and by day 28 in the one PR. FVIII activity was slightly slower to reach normal (median 31 days). It is difficult to make accurate comparisons of time to response for alternative therapeutic regimens, although response times in our cohort are certainly shorter than some $[10-12,16]$, particularly for suppression of the inhibitor [7]. This may be important in the prevention of early haemorrhagic deaths.

Response to treatment was not related to patient age or gender, nor to the presence or absence of underlying malignancy. Inhibitor level at diagnosis did not act as a guide to response, as suggested by some investigators [9], and in fact the case with the highest initial inhibitor level achieved CR.

We have found that the combination of prednisolone $1 \mathrm{mg} \mathrm{kg}^{-1} \mathrm{day}^{-1}$ with IVIg $2 \mathrm{~g} \mathrm{~kg}^{-1}$ in divided doses, in conjunction with active factor replacement for bleeding, is a successful approach to the suppression of acquired inhibitors. However, it is not possible to assess effectiveness of this regimen in the treatment of pregnancy or auto-immune associated acquired inhibitors as neither group was represented in our patient cohort. This treatment protocol is easy to administer, well-tolerated, and can be started with little delay at the time of diagnosis. The regimen produces a good response rate, and the speed of response, particularly the reduction in inhibitor level, is rapid, perhaps helping to prevent early haemorrhagic deaths.

\section{Acknowledgements}

Thanks to Frances McCall and Jim Conkie for performing the laboratory tests.

\section{References}

1 Lottenberg R, Kentro TB, Kitchens CS. A natural history study of 16 patients with factor VIII inhibitors receiving little or no therapy. Arch Intern Med 1987; 147: 1077-81.

2 Margolius A, Jackson DP, Ratnoff OD. Circulating anticoagulants: a study of 40 cases and a review of the literature. Medicine 1961; 40: 145-202.

3 Shapiro SS, Hultin M. Acquired inhibitors to the blood coagulation factors. Semin Thromb Haemost 1975; 1: 336-85.

4 Green D, Lechner K. A survey of 214 non-haemophiliac patients with inhibitors to factor VIII. Thromb Haemost 1981; 45: 200-3.

5 Hay CRM, Negrier C, Ludlam CA. The treatment of bleeding in acquired haemophilia with recombinant factor VIIa. Thromb Haemost 1997; 78: 1463-7.

6 Spero JA, Lewis JH, Hasiba U. Corticosteroid therapy for acquired FVIII:C inhibitors. Br J Haematol 1981; 48: $635-42$.

7 Green D, Rademaker AW, Briet E. A prospective randomised trial of prednisolone and cyclophosphamide in the treatment of patients with factor VIII antibodies. Thromb Haemost 1993; 70: 753-7.

8 Sultan Y, Kazatchkine MD, Nydegger U, Rossi F, Dietrich G, Algiman M. Intravenous immunoglobulin in the treatment of spontaneously acquired factor VIII:C Inhibitors. Am J Medicine 1991; 91: 35S-39S.

9 Herbst KD, Rapaport SI, Kenoyer DG, Stanton W, Feinstein DI. Syndrome of acquired inhibitor of factor VIII responsive to cyclophosphamide and prednisolone. Ann Intern Med 1981; 95: 575-8.

10 Rizza CR, Edgcumbe JOP, Pitney WR, Child JA. The treatment of patients having spontaneously occuring antibodies to antihaemophilic factor (factor VIII). Thromb Diath Haemorrhag 1972; 28: 120-7.

11 Lian EC-Y, Larcada AF, Chiu AY-Z. Combination immunosuppressive therapy after factor VIII infusion for acquired factor VIII inhibitor. Ann Intern Med 1989; 11: 774-8.

12 Saxena R, Mishra DK, Kashyap R, Choudhry VP, Mahapatra M, Bhargava M. Acquired haemophilia a study of ten cases. Haemophilia 2000; 6: 78-83.

13 Inhibitor Subcommittee of the Association of Haemophilia Clinic Directors of Canada. Suggestions for the management of factor VIII inhibitors. Haemophilia 2000; 6 (Suppl. 1): 52-9.

14 Kasper CK, Aledort LM, Counts RB. A more uniform measurement of factor VIII inhibitors. Thromb Diath Haemorrhag 1975; 34: 869-72.

15 McColl MD, Omran A, Walker ID, Lowe GDO. Acute renal failure complicating high-dose intravenous immunoglobulin therapy for acquired haemophilia. Haemophilia 1999; 5: 124-6.

16 Di Bona E, Schiavoni M, Castaman G, Ciavarella N, Rodeghiero F. Acquired haemophilia: experience of two Italian centres with 17 new cases. Haemophilia 1997; 3: 183-8. 